\title{
(IN)VISIBLE CHILDREN AND COVID-19: HUMAN TRAFFICKING IN PUBLIC HEALTH ETHICS
}

\author{
JAN GRESIL S. KAHAMBING*
}

\begin{abstract}
This paper appraises the link of public health ethics to human trafficking, especially on children. Taking from the more visible reports of child deaths from the virus, I focus on child health as an emphasis on how during this COVID-19 crisis, abuse and violence are also there albeit hidden. The range of clandestine operations concerning this issue in the Philippines seem to be broad and persistent. While local emergency ethics focuses on varying ways that contextualize - and locate special visible forms of - vulnerabilities from local citizens amid disasters, some vulnerabilities arise only within shrouded and surreptitious set-ups in public health ethics. Recognizing the hazards that lie in carefully categorizing visible and invisible vulnerabilities, human trafficking that preys on children is one invisible vulnerability that might gradually be pending in the sidelines. With the myriad of concerns on different fronts, there is a greater risk that this furtive issue might be treated subpar with other public health ethical considerations.
\end{abstract}

Keywords: Children; COVID-19; Pandemic; Human trafficking; Vulnerability

\section{INTRODUCTION}

In 2011, Habakus published Vaccine Epidemic: How Corporate Greed, Biased Science, and Coercive Government Threaten Our Human Rights, Our Health, and Our Children where one is confronted, in the end, with the choice of procuring a vaccine. But "the" vaccine seems to be nowhere in sight as the crisis no longer holds the status of an epidemic but a pandemic. The COVID-19 pandemic resonates around the world as the current crisis that, according to the World Health Organization in late September 2020, has already crossed a million deaths with more cases added each day. According to The Gale Encyclopedia of Children's Health (Krapp \& Wilson, 2005), a pandemic is a more serious influenza outbreak, lasting longer than the regional epidemic. States and institutions are at the forefront of a decision-making process that must discharge interim guidelines and actions while waiting for a solution. This setting brings into mind ethical considerations for public health and looks at the vantage points that might engender critical positions. One of these is the view on vulnerabilities that are already precarious and are made more precarious because of the pandemic. The forms that these took are varied and the variety is the species of a crucial genus, which is to say that each form of vulnerability warrants special considerations but its main point will always remain in each. Hence, whether it is a focus on disabilities, human rights, or the environment, they will always bring about ethical ramifications in many possible ways. The concern of this paper is to link public health ethics on a specific kind or kinds of vulnerability focused on children that lie within the interstice of human trafficking. It attempts to establish this link not only the visible kind but also the invisible kind of vulnerability. The question it asks is not 'is there an invisible kind of vulnerability in children during the pandemic?' but 'how might the interplay of visible 
and invisible vulnerabilities in children forward the discussion of public health ethics during the pandemic?'

\section{VISIBLE AND INVISIBLE VULNERABILITIES}

Vulnerability in ethics mostly pertains to its social component, so that the very term is more accurately stated as social vulnerability - an indicator of inequality. The experience of inequality can be felt through a lack of protection, insecurity, uncertainty, susceptibility to health damage, exclusion, and unequal access to health care (Arcos et al. 2016). Under this unequal access to health, there is perceived invisibility of social vulnerability that intensifies the risk factors of public health. For Dawson (2011), public health provides the foundations of public health ethics and meets the conditions for a sufficient rich or 'substantive' account of it. Such an account accepts the 'intrinsically social' dimension of public health that defines its ethics. Public health ethics in this sense is not just concerned with 'immediate' or visible factors, "but also with the prevention and reduction of harm as well as the wider determinants of health and many of the factors that shape the kind of society within which we wish to live" (p. 4). In this light, Lee and Morling (2020) call for the need for public health in a time of emergency that highlights various forms of vulnerabilities further calling for humanitarian considerations.

Going over the human condition, one can well note that there are hazards in creating a taxonomy between the visible and the invisible factors. This means that we should be careful in prioritizing those factors that may need expediting efforts and those that still need consolidating for a more comprehensive assessment. That humanitarian responses respond to natural but also political issues (Kleinman 2004) allows us to rethink the boundaries that are sometimes eroded when it comes to responding to crises. In this pandemic situation, visible forms of vulnerabilities point to the economic effects that are at risk. The choices are caught under the balance of pragmatic concerns and cautious calculation. It speaks of socio-economic factors in global proportions.

The pandemic thus reshapes the common form of vulnerability that its visibility points to a global emergency. But there are also special forms of visible vulnerability which include merging ethical considerations to local emergencies and ecological concerns such as disasters (Kahambing 2020). Without necessarily ruling out the non-categorization of these vulnerable experiences, one cannot also neglect the fact that risks have varying ranges of intensifications - from biological to socio-economic - and these rise to increasing rates depending on the events that are not anticipated fully (Powers 2016). Emergency ethics provide such visibility as disasters bring forth increasing vulnerabilities to those who are economically disadvantaged. In effect, conspicuous forms of disabilities arise as pressing concerns, backed by evidential assessments.

Invisible vulnerabilities are, on the contrary, not so much about the obvious ramifications of public health. It may refer to experiences in the areas of mental health with its exposure to marginalization, risks, and discrimination (Grossman and D'Augelli 2006). Youth experiences, particularly those that are not yet accepted in some social settings, may inform of hidden vulnerability. Similarly, those without or having unstable caregivers among students in universities also share an invisible vulnerability (Opsal and Eman 2018). The invisible conditions of certain individuals have very specific existential needs (Egargo and Kahambing 2020) and as such, cannot be seen in a singular way with a singular solution to boot.

In this pandemic, these may point to the plight of maids, manual scavengers, masons, porters, and daily wage workers (Samyukth 2020) and even religious pastors (Kahambing and Edilo 2020). However, the plight of children needs special attention as their fragile voice seems 
to render their vulnerability invisible. There is a crucial aspect in dealing with children in the pandemic because their concerns are both visible and invisible and are mostly catered only by the dependency they have on their guardians. The highlighting of their plight heavily depends on the focal point of research.

\section{VISIBLE CHILDREN IN COVID-19}

Children have a special place in public health. The so-called child public health is not a separate specialization in the field but is an essential part that "places the health of children in its full social, economic and political context" (Köhler 1998). With the pandemic crisis, the nexus that ties public health towards humanitarian considerations must deal with the focus on children. As such, this vital area needs to be contextualized. It should be noted however that the plight of children during this pandemic can be viewed within visible and invisible vulnerability.

The visibility part can be substantiated with children as part of the positive cases. In the Philippines, there are already cases of children dying from COVID-19 from early April to the middle of May. In Pangasinan, a 7-year old child died due to the virus, following from the underlying cause that is Pediatric Community-Acquired Pneumonia (Rappler 2020). In Davao City, three babies were added to the young fatalities of the crisis: a 25-day-old male infant, two baby girls - one is six-day-old and the other is four-month-old (Valdez 2020). The crucial point that one may draw from this is that the concept of 'herd immunity' may not apply since those who recovered may show symptoms of the virus again. For instance, the youngest COVID-19 survivor, Kobe Manjares, who was 5-day old when he contracted the virus, died after almost two months of recovery (Perez-Rubio 2020).

The socio-economic effect of the crisis on children is also visible. Children can no longer rely on their parents who lost their income due to quarantine measures (Ratcliffe and Fonbuena 2020). While there are government provisions in incongruous intervals, there is not enough guarantee that amelioration programs can sustain enough support to families having children, especially those with more than two in the household. But Anand says that there should be an aversion or less tolerance in inequalities that concern health than with income. This is because "the reasons involve the status of health as a special good, which has both intrinsic and instrumental value. Income, on the other hand, has only instrumental value" (Anand 2004). This must not, however, prevent us from thinking that because of deprived or economically less advantaged backgrounds, children may have less capacity - or capability to benefit (Marmot 2004).

Evidence-based assessments on the stable wellbeing of families with children can inform correspondences concerning public health. Data, which may be regarded as the "new oil' in a globalized world, can secure information for possible quick interventions in public safety. And yet movements that can ensure a fast-tracking of access towards assessments are mitigated by strict quarantine measures so that expediting evidence is slowed down. What this particularly points to is an aspect of public health that is not usually and easily reached in investigations - the issue of human trafficking, especially in children. The shift of emphasis towards the pandemic situation amplifies these gradual-moving investigations on the issue. To this definitive effect, children are rendered invisible.

\section{INVISIBLE CHILDREN IN HUMAN TRAFFICKING}

Herein lies the clandestine characteristic of human trafficking: it "is a vast, hidden, and perpetually evolving horror, and it is a difficult area on which to gather definitive data" (Villa 
2019). Albeit hidden, it should not be neglected and investigated in delayed operations. As it affects "multiple systems and the health of large groups, human trafficking is a public health issue. While the medical care system is primarily focused on the health of individuals, public health is concerned with the health and welfare of a people" (Chisolm-Straker and Stoklosa 2017; Italics mine). In this system of public health for the people, children are not excluded.

The International Labor Organization (ILO) prioritizes its antagonism to human trafficking acts that are focused on children and these comprise the compilation of the worst forms of child labor (WFCL). Since the inception of WFCL, there have been debates on its evolution and inclusion, particularly the exact minority age. However, the question of age evades the crux of the issue since the essential point is to look at its language: "the language of WFCL is also the language of human rights, calling for the immediate elimination of forms of slavery, trafficking, child soldiering and sexual and criminal abuse" (Cullen 2019).

In the Philippines, the issue of trafficking includes organ selling such as kidneys (Columb 2019), and slavery. The major concerns of the country, however, are "forced labour and sex trafficking" where "Filipino women and children from indigenous families and remote areas of the Philippines are trafficked for the purpose of sexual exploitation, and some are vulnerable to domestic servitude and other forms of forced labour" (Naranjo and Acharya 2019). What makes this hard to catch in terms of evidence is that these practices are nearly invisible. "Most of these workers are undocumented, making them vulnerable [...] to cultural practices that naturalize human trafficking" as the case of "Ibabao, a community near Cebu City, in which a common practice is sexual exploitation of children through cybersex and webcams" (Naranjo and Acharya 2019, p. 400). Local authorities condone this because "they needed the money." Consent can be questioned here as economic incentives and the circumstances of mistreatment from broken families make this practice assimilated as cultural elements. Girls are asked to do things for money, from stripping, dancing naked, to performing sexual acts. Lo (2015) reports that such acts can even include bestiality. The range of these acts vary from women to children in their capacities and exploitation easily bypasses these such aptitudes.

During this pandemic crisis, COVID-19 cases rising and other cases such as domestic violence dropping might mystify the issue of human trafficking. Evidence might just be delayed and full control of victims is most likely as they are more susceptible due to home arrest. As reported, "because they [vulnerable women and children] are more focused on the COVID-19 issue, the level of cooperation you get from them is not the same, which is quite understandable" (Ranada 2020). But this understanding requires a deeper probe into the cases at hand.

Amid quarantine, a 5-year-old girl with two other kids in Luzon was caught performing sexual acts for online transactions connected to Australia. This act of sexual violence was forced by a 41-year-old woman who utilized their living room as a set-up for a cybersex crime. The children's home, as it were, provided locus for unhomely enterprise.

A similar case of doing lewd acts on camera also happened to a 3-year-old along with other six kids as they were forced by a 25 -year-old woman who included her four children among the seven. What is distinct in this is the fact that people who are related to these children and who are no longer function in their right frame of mind can also exploit them under false presentations of authority. For instance, aside from webcam operations, 5 other cases of child abuse also include incest as house confinement intensifies (Ranada 2020).

The perpetuity of these cases in the country is sustained by many factors. To cite, "the wide use of English, availability of internet connections and widespread international cash transfer systems have combined with long-entrenched poverty and wide access to vulnerable kids to allow many abuses to happen in the Philippines" (Associated Press 2020). Studies have 
then determined that the Philippines 'tops world for online child sex abuse' and has become a global hotspot (France-Presse 2020).

Commercial sexual exploitation of children (CSEC) has a global prevalence in almost every country, yet there are no reliable statistics that can inform of this phenomenon (Hounmenou 2019). These render more invisible the vulnerability in children. Among the forms of child sex tourism, child prostitution is said to be the most prevalent form of CSEC. But despite being in the hot spot position for online sex abuse, there is an asymmetrical relation because child pornography has the least number of research. There are also legal implications of this that run counter to the ethical presuppositions that can enforce normative actions. An 'Affidavit of Desistance' is being issued with the victims that can drop the charges against the traffickers. As Naranjo and Acharya (2019) assert, following from Abocejo and Gubalane (2013): "this psychological and cultural aspect is very difficult to fight against, because most of the victims do not consider themselves as victims of human trafficking" (p. 45).

\section{FRAMING TRAFFICKING FROM PUBLIC HEALTH TO PUBLIC HEALTH ETHICS}

Awareness of public health must, therefore, not render human trafficking on children more invisible to the radar. With the many concerns bombarding authorities in terms of the economy and public safety, this important dimension of public health must be brought to the fore as well. The internet may be an apparatus that help perpetuate the cases, but it can also be utilized in the gathering of data to spot the operations. Media coverage through investigative journalism can make such operations transparent to the public, allowing its networks to slow down, if not malfunction. The US Department of Health \& Human Services stresses the importance of framing Human Trafficking as a Public Health Issue (2016):

\footnotetext{
We need to energize public health's role in the fight against human trafficking because the field has a fundamental belief that life can be improved and societies can change even in the midst of seemingly entrenched interests. Public health will invest in rigorous research to gather the data to change public understanding and behaviour that enable human trafficking. Public health approaches will inform policies that recognize human trafficking as an inter-connected issue to other forms of violence and systemic inequities. And public health has a history of addressing issues with urgency - like preventing car accidents and reducing tobacco use - even if they occur to a relative minority of our population because we can see the broader societal and multi-generational consequences.
}

That being said, there is optimism that even if "in recent years, the number of trafficking prosecutions has skyrocketed in the Philippines," rescue operations have also increased (Villa 2019). Ethical considerations can refer again to the sociality that underlies the framing of public health. Interventions that fight against oppression and slavery in the human condition can tap law enforcement, social service providers, and first responders. Moreover, specificities in populations are local and culturally relevant so that experiences of stigma, exclusion, and even cultural appropriations can make a better and informed decision in the approaches for prevention.

In transitioning to public health ethics, framing of issues must go beyond a singular approach in either interpretation of statistics or particular anthropological lenses. Allowance of equity must ensure that both approaches are necessary for enforcing proper interventions. Amartya Sen already notes of the importance of being open to using external - statistically and broadly informed - and internal - anthropological and locally informed - perspectives (Sen 2004). Says Sen, 
What has to be avoided above all is the narrowness and limitation of choosing either the internal or the external perspective on its own, and rejecting the other. We have to go beyond the self-inflicted injury of methodological narrowness and dogmatism - of either kind. Practical reason demands open-minded epistemology (p. 268).

This 'open-minded epistemology' might prepare research in public health ethics to confront the idea that the very concept of inequality in itself is complex. The complexity has to be internalized so that the situation determines the reality of "divisions of interest and perspective among all of us, including across nations" and that shift to a broader and more catholic or openminded framework "to address the causes of health inequality can thus be politically divisive, both domestically and internationally" (Daniels 2011, p. 208; see also Temkin 1993).

What the discussion of children in their visible and invisible vulnerabilities opens up is the interconnection of exposures that need the inclusive hospitality of ethical considerations. Some of the cases that are presented need echoing so that voices are heard and data can speak. Human trafficking remains to be a damaging activity when directed to children.

Since the network that enslaves children are pervasive and connected, public health ethics must establish strong coordination within its normative contestations. With the myriad of concerns on different fronts, there is a greater risk that this furtive issue might be treated subpar with other public health ethical considerations. The contention is that children should not be caught up with this and must be given special and full attention as persons with equally important human rights amid the epistemological and social prioritizations.

\section{CONCLUSION}

An ethics that remains consistent with its resolve of crosschecking evidence-based and openminded epistemology can, in principle, bring about alert means of deciding inconspicuous public health issues. Philosophical approaches can combine with qualitative and quantitative analyses in highlighting and giving voice to the numerical descriptions that preoccupy the quotidian reports of cases. In conclusion, this paper notes that an interplay of visible and invisible vulnerabilities enables the discussion of public health ethics to be vigilant over matters that concern children during this pandemic. It seeks to deflect from the undermining of children as part and parcel only of the pandemic concerns and brings into light their full embodiment and core place in public health.

\section{REFERENCES}

Abocejo, F., and F. Gubalane. 2013. Implementation of the Anti-Human Trafficking Law in Cebu City, Philippines. International Forum, 16(1).

Anand, S. 2004. The Concern for Equity in Health. In Sudhir Anand, Fabienne Peter, and Amartya Sen, eds., Public Health, Ethics, and Equity (pp. 15-20). Oxford University Press.

Arcos, E., M. Canales, L. A. Muñoz, M. C. Toffoletto, X. Sánchez, and A. Vollrath. 2016. Invisibility of Social Vulnerability and Social Rights to a Comprehensive Health Care in Chile. Texto \& Contexto - Enfermagem, 25(4), https://doi.org/10.1590/010407072016006150015.

Associated Press. 2020. Study: Philippines A global Hot Spot for Online Child Abuse. https://www.voanews.com/east-asia-pacific/study-philippines-global-hot-spot-onlinechild-abuse. 
Chisolm-Straker M., and H. Stoklosa. 2017. Human Trafficking Is a Public Health Issue: A Paradigm Expansion in the United States. Springer.

Columb, S. 2019. Organ Trafficking: Transplant Tourism and Trafficking in Persons for the Removal of Organs. In Jennifer Byrson Clark and Sasha Poucki, eds., The Sage Handbook of Human Trafficking and Modern Day Slavery (pp. 155-173). SAGE.

Cullen, H. 2019. The Evolving Concept of Worst Forms of Child Labor. In Jennifer Byrson Clark and Sasha Poucki, eds., The Sage Handbook of Human Trafficking and Modern Day Slavery (pp. 139-154). SAGE.

Daniels, N. 2011. Equity and population health. Toward a broader bioethics agenda. In Angus Dawson (ed.), Public Health Ethics. Key Concepts and Issues in Policy and Practice (pp. 191-210). Cambridge University Press.

Dawson, A. 2011. Resetting the Parameters: Public Health as the foundation for Public Health Ethics. In Angus Dawson (ed.), Public Health Ethics. Key Concepts and Issues in Policy and Practice (pp. 1-19). Cambridge University Press.

Egargo, F.J. and J. G. Kahambing. 2020. Existential hope and humanism in COVID-19 suicide interventions. Journal of Public Health, 10.1093/pubmed/fdaa171.

France-Presse, A. 2020. Philippines tops world for online child sex abuse: Study. https://www.thejakartapost.com/seasia/2020/05/21/philippines-tops-world-for-onlinechild-sex-abuse-study.html.

Grossman, A., and A. D'Augelli. 2006. Transgender Youth: Invisible and vulnerable. Journal of Homosexuality, 51(1), 111-128.

Habakus, L. K. 2011. Vaccine Epidemic: How Corporate Greed, Biased Science, and Coercive Government Threaten Our Human Rights, Our Health, and Our Children. Skyhorse Publishing, Inc.

Hounmenou, C. 2019. Commercial Sexual Exploitation and Sex Trafficking of Children in the West African Region. In Jennifer Byrson Clark and Sasha Poucki, eds., The Sage Handbook of Human Trafficking and Modern Day Slavery (pp. 360-382). SAGE.

Kahambing, J.G. 2020. Public Health and Local Emergency Ethics: Vulnerability in Eastern Samar, Philippines. Public Health. https://doi.org.0.1016/j.puhe.2020.05.032.

Kahambing, J.G., and S. R. Edilo. 2020. Stigma, exclusion, and mental health during COVID19: 2 cases from the Philippines. Asian Journal of Psychiatry, 54. https://doi.org.10.1016/j.ajp.2020.102292.

Kleinman A. 2004. Ethics and Experience: An Anthropological Approach to Health Equity. In Sudhir Anand, Fabienne Peter, and Amartya Sen, eds., Public Health, Ethics, and Equity (pp. 269-282). Oxford University Press.

Köhler, L. 1998. Child Public Health. A new basis for child health workers. European Journal of Public Health, 8, 253-255.

Krapp, K., and J. Wilson. 2020. The Gale Encyclopedia of Children's Health: Infancy Through Adolescence, vols. 1-4. Michigan: Thompson Gale.

Lee, A., and Morling, J. 2020. COVID19 - The need for Public Health in a time of emergency. Public Health. https://linkinghub.elsevier.com/retrieve/pii/S0033350620300913.

Lo, B. 2015. Child Cybersex in the Philippines. Documentary. Philippines: Chinese State Television Center, Assignment Asia.

Marmot, M. 2004. Social Causes of Social Inequalities in Health. In Sudhir Anand, Fabienne Peter, and Amartya Sen, eds., Public Health, Ethics, and Equity (pp. 37-61). Oxford University Press.

Naranjo D.L., and A. K. Acharya. 2019. Impacts of Cultural Practices in Anti-Trafficking Policies in Southeast Asia. In Jennifer Byrson Clark, and Sasha Poucki, eds., The Sage Handbook of Human Trafficking and Modern Day Slavery (pp. 397-407). SAGE, 2019. 
Opsal, T., and R. Eman. 2018. Invisible vulnerability: Participant perceptions of a campusbased program for students without caregivers. Children and Youth Services Review, 94, 617-627.

Perez-Rubio, B. 2020. Youngest COVID-19 survivor in Philippines 'Baby Kobe' dies. https://www.philstar.com/headlines/2020/06/04/2018690/youngest-covid-19-survivorphilippines-baby-kobe-dies.

Powers, M. 2016. Vulnerable Populations in the Context of Public Health Emergency Preparedness Planning and Response. In Bruce Jennings, John Arras, Drue Barrett, and Barbara Ellis, eds., Emergency Ethics: Public Health Preparedness and Response (pp. 135-154). Oxford University Press.

Ranada, P. 2020. During coronavirus lockdown: Abused women, children more vulnerable. https://www.rappler.com/newsbreak/in-depth/260072-during-coronavirus-lockdownabused-women-children-more-vulnerable.

Rappler. 2020. Girl, 7, dies of coronavirus disease in Pangasinan town. https://www.rappler.com/nation/256682-seven-year-old-girl-coronavirus-casespangasinan-april-1-2020.

Ratcliffe, R., and C. Fonbuena. 2020. Chaos in Manila as Philippines launches coronavirus quarantine measures. https://www.theguardian.com/world/2020/mar/17/south-eastasian-countries-impose-coronavirus-restrictions.

Samyukth, S. 2020. The Visible Invisible: Vulnerability exposed by COVID-19 in India. https://thedevelopmentaficionado.com/2020/05/07/the-visible-invisible-vulnerabilityexposed-by-covid-19-in-india/.

Sen, A. 2004. Health Achievement and Equity: External and Internal Perspectives. In Sudhir Anand, Fabienne Peter, and Amartya Sen, eds., Public Health, Ethics, and Equity (pp. 263-268). Oxford University Press.

Temkin, I. 1993. Inequality. New York: Oxford University Press.

U.S. Department of Health and Human Services 2016. The Power of Framing Human Trafficking as a Public Health Issue. https://www.acf.hhs.gov/otip/resource/publichealthlens.

Valdez, W.E. 2020. 25-day-old infant dies of COVID-19 in Davao. https://news.mb.com.ph/2020/05/11/25-day-old-infant-dies-of-covid-19-in-davao/.

Villa, M. 2019. Slaves Among Us: The Hidden World of Human Trafficking. Rowman \& Littlefield.

\section{JAN GRESIL S. KAHAMBING}

Leyte Normal University

Paterno St., Tacloban City

Leyte 6500, Philippines

*Corresponding author: vince_jb7@ @otmail.com. 